\title{
MISKONSEPSI PADA MATERI GUGUS FUNGSI DAN POTENSI STRATEGI KONFLIK KOGNITIF BERBASIS MULTIPEL REPRESENTASI DALAM MEMPERBAIKINYA
}

\author{
Maria Ulfaha ${ }^{a}$, Subandib $^{\mathrm{b}}$, Munzilc $^{\mathrm{c}}$ \\ a,b,cJurusan Kimia FMIPA Universitas Negeri Malang
}

\begin{abstract}
Abstrak - Gugus fungsi merupakan salah satu materi kimia organik yang masih dianggap sulit oleh sebagian mahasiswa dan memiliki cakupan yang luas. Kesulitan belajar pada materi ini dikarenakan beberapa faktor, yakni:sifat multidimensi materi kimia organik, sikap pebelajar terhadap pembelajaran kimia organik, dan adanya miskonsepsi. Untuk mengatasi miskonsepsi materi gugus fungsi akan digunakan strategi konflik kognitiv. Karakteristik materi yang multidimensional akan lebih efektif bila materi ajar dibelajarkan dengan multipel representasi. Makalah ini akan mengkaji beberapa miskonsepsi yang dialami mahasiswa pada materi gugus fungsi dan keefektivitan strategi konflik kognitiv dalam memperbaiki miskonsepsi tersebut. Metode kajian yang dgunakan adalah studi literatur.
\end{abstract}

Kata kunci: gugus fungsi, miskonsepsi, konflik kognitif, multipel representasi

\begin{abstract}
The functional group is one of the organic chemicals that is still considered difficult by some students and has a wide range. Learning difficulties in this material are due to several factors, namely: the multidimensional nature of organic chemistry, the attitude of learners to the learning of organic chemistry, and the existence of misconception. To overcome the functional cluster material misconception will be used cognitive conflict strategy. Multidimensional material characteristics will be more effective when teaching materials are taught with multiple representations. This paper will examine some misconceptions experienced by students on the functional group matter and effectiveness of cognitive conflict strategies in improving these misconceptions. The study method used is literature study.
\end{abstract}

Keywords: funcional groups, misconception, cognitive conflict, multiple representation

\section{PENDAHULUAN}

Gugus fungsi merupakan materi dasar kimia organik yang dipelajari di matakuliah pengantar kimia organik. Sebagai materi dasar, mahasiswa diharapkan memahami secara mendalam materi tersebut. Materi ini merupakan salah satu materi yang dianggap sulit dan mempunyai wilayah topik yang luas (Hassan, Hill \& Reid, 2004; Knudtson, 2015; Akuzzu \& Uyulgan, 2015). Fakta di lapangan menunjukkan bahwa masih terjadi miskonsepsi pada materi tersebut. Hasil penelitian Akuzzu \& Uyulgan (2015) menunjukkan bahwa pemahaman mahasiswa mengenai konsep yang berkaitan 
dengan gugus fungsi masih termasuk dalam kategori rendah dan sebagian besar mengalami miskonsepsi.

Upaya untuk memperbaiki kesalahan konsep/ miskonsepsi pada materi gugus fungsi tidaklah mudah. Hal ini karena miskonsepsi cenderung bertahan dan sulit untuk menerima pemahaman baru yang lebih ilmiah (Berg, 1991). Mahasiswa harus dibelajarkan dengan strategi yang menciptakan kondisi konflik dalam dirinya sehingga menimbulkan ketidakseimbangan dan memungkinkan untuk menerima konsep yang benar secara keilmuan. Sejalan dengan pendapat Kavanaugh dan Moomaw (dalam Effendy, 2002) konflik kognitif dapat ditimbulkan apabila pengajar menciptakan suatu situasi di mana mahasiswa menemukan kesukaran-kesukaran sehubungan dengan konsep salah yang dimilikinya. Pertanyaan-pertanyaan yang diajukan dalam situasi konflik dapat membantu mahasiswa dalam mengatasi atau menyelesaikan konflik yang ada. Diharapkan dengan strategi konflik kognitif dapat merekonstruksi miskonsepsi mahasiswa menjadi pemahaman yang benar secara keilmuan.

Miskonsepsi kimia bisa jadi terjadi karena mahasiswa tidak dapat mengkaitkan antara ke tiga representasi kimia yakni makroskopis, submikroskopis dan simbolik (Akuzzu \& Uyulgan, 2015). Pembelajaran kimia yang dilakukan selama ini hanya mencakup level simbolik dan makroskopis (Gabel, 1999), sehingga mahasiswa mengalami kesulitan menghadapi konsep-konsep kimia organik yang mencakup aspekaspek multipel representasi. Akuzzu \& Uyulgan (2015) menyarankan bahwa untuk meningkatkan pemahaman konsep mahasiswa pada kimia organik khususnya pengajar seharusnya menggunakan strategi pembelajaran yang efektif dengan mengkaitkan aspek multipel representasi. Gilbert \& Treagust (2009) dan Sirhan (2007) menyatakan bahwa dengan menghubungkan representasi makroskopik, mikroskopik dan simbolik akan sangat membantu dalam meningkatkan penguasaan konsep-konsep kimia. Selain diperbaiki dengan strategi konflik kognitif, dosen harus memperhatikan aspek multipel representasi dalam memperbaiki miskonsepsi mahasiswa. Hal ini agar mahasiswa lebih mudah dalam memahami konsep dan pemahaman konsep diperoleh secara utuh.

\section{PEMBAHASAN}

\section{Miskonsepsi dan Dampaknya dalam Pembelajaran}

Mahasiswa memiliki pengetahuan awal yang berbeda-beda pada saat memasuki kelas. Selama proses pembelajaran berlangsung, mahasiswa akan mengonstruk pengetahuan baru yang diterima berdasarkan pengetahuan awal, kemampuan dan pengalaman masing-masing. Apabila konsep awal yang dimiliki tidak sesuai dengan konsep sains maka akan menimbulkan miskonsepsi, prakonsep atau konsep alternatif dalam proses pembelajaran (Pérez et al., 2017). Beberapa hal tersebut akan berdampak negatif terhadap pembelajaran dan menyebabkan kesulitan untuk membangun sebuah konsep yang sesuai dengan gagasan yang diterima secara sains.

Miskonsepsi dapat ditemukan di seluruh wilayah ilmu sains. sebagai contoh, dalam fisika, ditemukan sekitar 85\% siswa sekolah menengah mengalami miskonsepsi pada bahasan materi tentang gaya. Pada kajian ilmu biologi, salah satu miskonsepsi yang ditemukan yakni tumbuhan mendapatkan nutrisi dari tanah. Mahasiswa juga 
mengalami hal tersebut, meskipun sudah mempelajari fotosintesis yang merupakan proses ilmiah tumbuhan yang menghasilkan nutrisi (Taber, 2002). Begitu juga dalam kajian ilmu kimia, miskonsepsi yang terjadi pada siswa sangat kompleks. Nakhleh (1992) menyebutkan bahwa miskonsepsi mengenai sifat partikulat materi terjadi pada semua jenjang pendidikan, dari pendidikan dasar hingga tingkat universitas.

Herron (1996) membagi miskonsepsi ke dalam dua kategori. Kategori yang pertama berkaitan dengan apa yang terjadi secara fisika. Mahasiswa meyakini bahwa suatu objek yang berat selalu tenggelam di dalam air, gelembung yang terlihat pada saat air mendidih adalah hidrogen atau oksigen, air yang mendidih dengan cepat berada pada suhu yang lebih tinggi daripada air yang mendidih dengan lambat, dan suatu materi akan mengalami perubahan massa pada saat melebur atau mendidih. Beberapa gagasan tersebut secara sederhana bertentangan dengan fakta empiris.

Kategori yang kedua berkaitan dengan penjelasan mahasiswa tentang sesuatu yang terjadi di alam. Banyak penelitian yang telah dilakukan pada konsep mahasiswa tentang panas, sebagai contoh (Albert, 1978; Erickson, 1979; Hewson, 1989; Shayer \& Wylen, 1981) seperti yang dikutip oleh Herron (1996). Secara umum mahasiswa memahami panas secara istilah pada teori tentang kalor panas, seperti yang dijelaskan oleh Fuchs (1987) dan secara internal bersesuaian dengan teori termodinamika yang dikembangkan pada konsep tentang kalor. Konsep yang ada pada mahasiswa menjelaskan apa yang terjadi di alam. Namun, penjelasan tersebut berbeda dengan konsep yang diterima sains. Pada intinya banyak gagasan yang dilabeli sebagai miskonsepsi bukan tentang apa yang terjadi tapi kesalahan penjelasan tentang apa yang terjadi. pada kebanyakan kasus penjelasan tersebut dianggap logis menurut sudut pandang mahasiswa, secara konsisten mengenai pemahaman mereka tentang alam dan resistan untuk diubah.

\section{Miskonsepsi Materi Gugus Fungsi}

Ciri-ciri struktur senyawa organik berbeda antara satu dengan yang lain. Ciri-ciri struktur ini menentukan geometri molekul, sifat fisika, reaktivitas, dan bagian dari gugus fungsi. Gugus fungsi adalah sebuah atom atau gugus atom-atom yang memiliki karakteristik kimia dan sifat fisika, dan merupakan bagian molekul yang reaktif. Adapun konsep-konsep yang terjadi miskonsepsi pada mahasiswa yakni berkaitan dengan gaya antarmolekul, alkohol dan eter, aldehid dan keton serta asam karboksilat dan ester (Akuzzu \& Uyulgan, 2015).

Penelitian mengenai miskonsepsi mahasiswa pada materi gugus fungsi telah dilakukan oleh Akuzzu dan Uyulgan (2015). Hasil penelitian tersebut melaporkan bahwa miskonsepsi mahasiswa pada materi gugus fungsi disebabkan karena siswa tidak memahami secara mendalam materi mengenai sifat fisika gugus fungsi, gaya antarmolekul, keasamaan dan kebasaan, oksidasi reduksi, stereoisomerisme, struktur isomer, senyawa aromatis dan alifatis, serta konsep-konsep lain yang berkaitan. Faktor lain yang menyebabkan terjadinya miskonsepsi pada kimia organik yakni pengetahuan awal yang kurang, yang mana pengetahuan tersebut berkaitan dengan konsep yang dipelajari dikimia organik. 
Miskonsepsi yang ditemukan pada penelitian Akuzzu \& Uyulgan (2015), mahasiswa menyatakan bahwa eter merupakan senyawa yang mempunyai gugus fungsi nonpolar sesuai struktur molekulnya. Miskonsepsi ini dikarenakan kurangnya pengetahuan awal tentang struktur molekul dan polaritas molekul yang seharusnya telah dikuasai pada matakuliah sebelumnya yakni kimia dasar. Miskonsepsi lain yang ditemukan yakni "ester terbentuk dari oksidasi keton" dan "keton terbentuk dari oksidasi polialkohol". Mahasiswa tidak dapat membedakan produk oksidasi dan reduksi keton dengan diol dan polialkohol, meskipun termasuk mono-alkohol. Konsep lain yang ditemukan mengalami miskonsepsi yakni pada konsep reduksi oksidasi. Mahasiswa membuat generalisasi bahwa "alkohol yang teroksidasi akan menghasilkan asam karboksilat", tanpa menganalisis konsep dari oksidasi alkohol primer, sekunder dan tersier (Akuzzu \& Uyulgan, 2015).

\section{Strategi Konflik Kognitif berbasis Multipel Representasi untuk Mengatasi Miskonsepsi}

Strategi yang dapat digunakan untuk memperbaiki miskonsepsi ada tiga yaitu konflik kognitif, analogi dan diskusi kooperatif (Limón, 2001). Strategi konflik kognitif dapat ditimbulkan apabila pengajar menciptakan suatu situasi dimana mahasiswa menemukan kesukaran-kesukaran sehubungan dengan pengetahuan yang telah dimilikinya (miskonsepsi). Menurut Kavanaugh dan Moomaw (dalam Effendy, 2002) pada situasi konflik pengajar dapat mengajukan pertanyaan-pertanyaan yang dapat mengatasi atau menyelesaikan konflik yang terjadi dalam pikiran mahasiswa dan diharapkan dapat memperbaiki miskonsepsinya.

Effendy (2002) menyatakan bahwa strategi konflik kognitif merupakan strategi untuk membuat siswa menjadi konflik terhadap konsep-konsep atau pengetahuan yang telah dimilikinya. Konflik ini mengakibatkan skema yang dimiliki oleh siswa menjadi tidak seimbang (disekuilibrium). Keadaan disekuilibrium ini dapat diarahkan ke keadaan ekuilibrium yang baru melalui proses ekuilibrasi. Penerapan strategi ini menuntut untuk diperhatikannya beberapa hal yang perlu, di antaranya adalah: (1) profil pengetahuan awal siswa; (2) strategi dilakukan secara hati-hati agar jangan sampai memperkuat miskonsepsi siswa; (3) strategi yang diterapkan harus mampu menggoyahkan stabilitas miskonsepsi siswa. Jika siswa telah ragu atau goyah terhadap gagasannya, maka diharapkan mereka akan mau merekonstruksi gagasannya yang salah.

Dalam menciptakan situasi konflik kognitif mahasiswa akan lebih mudah menerima materi jika dijelaskan dengan mengkaitkan multipel representasi. Hal ini karena ilmu kimia mencakup tiga macam tingkat representasi yaitu makroskopik, submikroskopik, dan simbolik. Ketiga tingkat representasi tersebut dirangkai menjadi sebuah kesatuan yang saling berhubungan dalam pembelajaran kimia sehingga materi yang disampaikan dapat diterima dengan baik oleh mahasiswa. Dengan ketiga tingkat representasi tersebut menjadi kunci keberhasilan memahami konsep-konsep kimia dengan baik (Wu et al, 2001; Gilbert \& Treagust, 2009).

Hubungan antar tingkat dalam multipel representasi pada ilmu kimia digambarkan pada Gambar 1. 


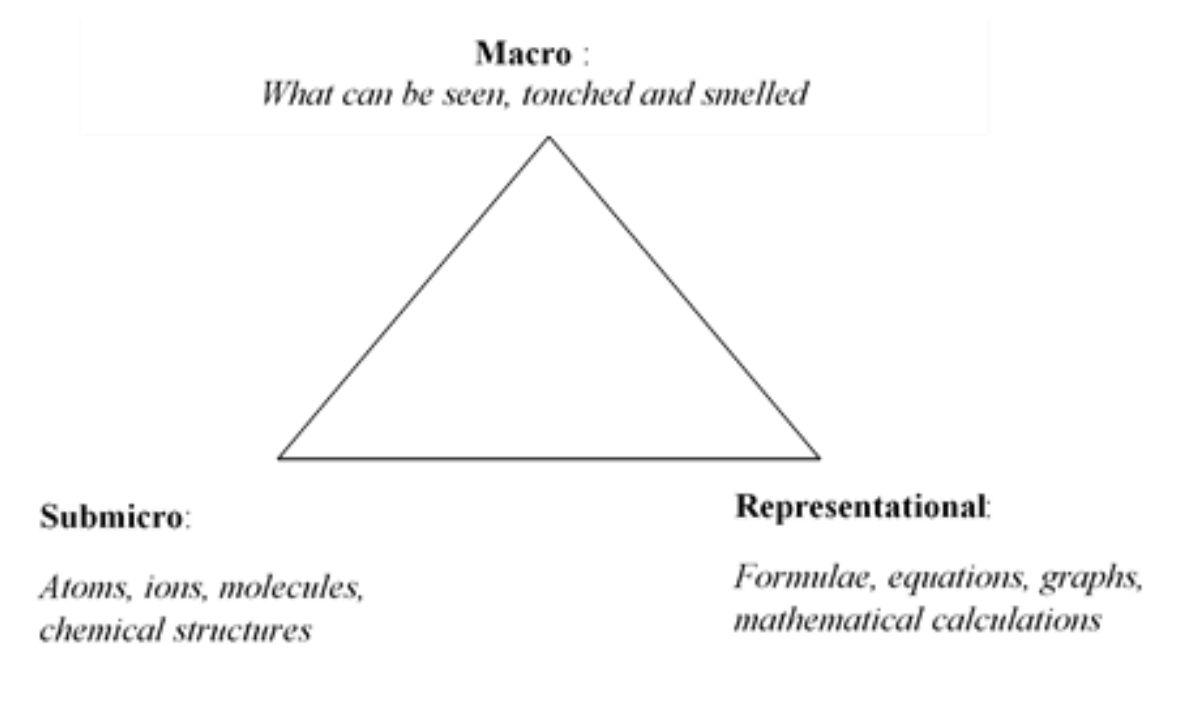

Gambar 1 “Chemical Triangel” Menggambarkan Interkoneksi Multipel Representasi (Sirhan, 2007), yaitu Makro, Submikro dan Simbolik (Representasi)

Pembelajaran untuk mengatasi miskonsepsi dengan multipel representasi telah dilakukan oleh Pikoli \& Sihaloho (2014) pada materi Hidrolisis Garam dan menunjukkan penurunan miskonsepsi dengan rata-rata 13,6 \%. Penelitian lain yakni Nilawati (2016) melakukan perbaikan kesalahan konsep dengan strategi yang sama pada materi stoikiometri dan efektif dalam mengurangi kesalahan konsep siswa. Penerapan strategi konflik kognitif untuk memperbaiki miskonsepsi telah dilakukan oleh Jusniar (1998) yang mana strategi konflik kognitif dapat meminimalkan kesalahan konsep siswa pada materi termokimia. Selain itu Dinihari (2004) melaporkan bahwa penerapan strategi konflik kognitif efektif mengurangi salah konsep siswa pada materi ikatan kimia.

\section{KESIMPULAN}

Miskonsepsi pada materi gugus fungsi perlu diatasi agar tidak menyebabkan kesulitan dan miskonsepsi pada materi selanjutnya. Salah satu upaya untuk memperbaiki miskonsepsi yakni dengan strategi konflik kognitif berbasis multipel representasi. Hal ini karena salah satu kunci utama dalam membelajarkan kimia organik adalah dengan mengaitkan ketiga tingkat representasi. Adanya keterkaitan yang saling mendukung antar tingkat representasi maka sangat membantu dalam memahami konsep-konsep kimia organik (Gilbert \& Treagust, 2009). Upaya dalam memperbaiki miskonsepsi dilakukan dengan memberikan fakta-fakta, anomali yang kontradiktif, sehingga mahasiswa dapat menyadari pemahamannya yang salah. Kemudian dibantu dengan memberikan pertanyaan dan informasi sehingga terjadi ekulibrasi. Semua proses tersebut merupakan rangkaian dalam strategi konflik kognitif. 


\section{DAFTAR RUJUKAN}

Akuzzu, N \& Uyulgan, A. 2015. An Epistemological Inquiry into Organic Chemistry Education: Exploration of Undergraduate Students' Conceptual Understanding of Functional Group. Chemistry Education Research and Practice. DOI: 10.1039/c5rp00128e

Berg, Van Den e. 1991. Miskonsepsi Fisika dan Remediasi. Salatiga: Universitas Kristen Satya Wacana.

Dinihari, P. 2004. Analisis Kesalahan Konsep dalam Ikatan Kimia berdasarkan Gambaran Mikroskopis pada Siswa kelas 1 SMU Negeri Sumberpucung dan Upaya Memperbaikinya dengan Menggunakan Strategi Konflik Kognitif. Tesis tidak diterbitkan. Malang: Pascasarjana Program Studi Pendidikan Kimia Universitas Negeri Malang.

Effendy. 2002. Upaya untuk Mengatasi Kesalahan Konsep dalam Pengajaran Kimia dengan Menggunakan Strategi Konflik Kognitif. Media Komunikasi Kimia, 2 (6): 1-22.

Gabel, D, L. 1999. Improving Teaching and Learning through Chemistry Education Research: A Look to the Future. Journal of Chemical Education. 76(4): 548-554.

Gilbert, J. K. \& Treagust, D. F. 2009. Multiple Representation in Chemical Education: Models and Modelling in Science Education. Dordrecht: Springer.

Hassan, A. K., Hill, R. A., Reid, N. 2004. Ideas Underpinning Success in an Introductory Course in Organic Chemistry. University Chemistry Education. 8: 40-51

Herron, Dudley J. 1996. The Chemistry Classroom Formulas for Successful Teaching. The American Chemical Society: Washington DC

Johnstone, A. H. 2000. Teaching Of Chemistry-Logical or Psychological?. Chemistry Education Research and Practice in Europe, 1 (1): 9-15.

Jusniar. 1998. Penggunaan Strategi Konflik Kognitif sebagai Upaya Memperkecil Kesalahan Siswa dalam Memahami Konsep-konsep Termokimia. Tesis tidak diterbitkan. Malang: Pascasarjana Program Studi Pendidikan Kimia Universitas Negeri Malang.

Knudtson, C.A. 2015. ChemKarta: A Card Game for Teaching Functional Group in Undergraduate Organic Chemistry. Journal of Chemical Education. 92(9): 1514-1517.

Limón, Margarita. 2001. On The Cognitive Conflict as an Instructional Strategy for Conceptual Change: A Critical Appraisal. Learning and Instruction 11(357-380).

Nakhleh, M. B. 1992. Why Some Students Don't Learn Chemistry. Journal of Chemical Education. 69 (3): 191-196.

Nilawati, P.A. 2016. Identifikasi Kesalaban Konsep pada Materi Stoikiometri di SMA dan Upaya Perbaikannya dengan Strategi Pembelajaran Multipel Representasi. Tesis tidak diterbitkan. Malang: Pascasarjana Program Studi Pendidikan Kimia Universitas Negeri Malang.

Pérez, Ballester J. R, Pérez, Ballester M. E, Calatayud, M. L, Lopera, Garcia R, Montesinos, Sabater J. V, Gil, Trilles E. 2017. Student's Misconceptions on Chemical Bonding: A Comparative Study between High School and First Year University Students. Asian Journal of Education and e-Learning, 5. ISSN: 2321-2454

Pikoli, M., \& Sihaloho, M. 2014. Implementasi Pembelajaran dengan Menginterkoneksikan Multipel Representasi pada Materi Hidrolisis Garam untuk Mereduksi Miskonsepsi Siswa. Makalah disajikan dalam Prosiding Seminar Nasional Kimia, Jurusan Kimia FMIPA Universitas Negeri Surabaya, Surabaya, 20 September, (Online), (fmipa.unesa.ac.id/kimia/wp.../87-97-MasridPikoli.pdf)

Sirhan, G. 2007. Learning Difficulties in Chemistry: An Overview. Journal of Turkish Science Education, 4 (2): 2-20

Taber, K.S. 2002. Chemical Misconceptions - Prevention, Diagnosis and Cure: Theoretical background (Vol. 1). London: Royal Society of Chemistry.

Wu H. K., Krajcik, J. S., \& Soloway, E. 2001. Promoting Understanding of Chemical Representastions: Students' Use of a Visualization Tool in the Classroom. Journal of Research in Science Teaching, 38: 821-842 